\title{
Education design: theory, practice and policy
}

\author{
S. P. Heyneman ${ }^{1}$
}

Published online: 8 August 2016

(c) Education Research Institute, Seoul National University, Seoul, Korea 2016

In October, 2015, scholars, administrators, journalists, teachers and students met at Seoul National University to discuss coming issues. The papers which appear in this special issue of the APER were among the papers discussed at that meeting. They have been vetted for quality, originality and importance. We begin with a keynote address titled New Directions in Policy Borrowing Research written by Gita Steiner-Khamsi. Her point concerns the propensity for public policies to appear with some regularity in different parts of the world-teacher performance pay, international tests of academic achievement, decentralization, diversification of finance. The question is how do these public policies migrate? By what mechanism? Through which kinds of incentives? Her paper deals with the research on this issue. Her point is that policy borrowing may help to mobilize financing in an environment of political competition and the concern about falling behind. Her article provides an overview of this arena and the growing research associated with it.

Among the more popular innovations in public policy, Conditional Cash Transfers (CCT) have been employed in Latin America, sub-Saharan Africa and Asia. They have been used to help stimulate higher levels of school attendance, participation in child nutrition programs and higher levels of school achievement. In an article by Kye Woo Lee and Miae Hwang, the question concerns the effectiveness of a CCT program in Indonesia whose purpose is to divert underage children from the labor market and encourage them to attend school. Lee and Hwang discover

S. P. Heyneman

S.heyneman@vanderbilt.edu

1 Professor (Emeritus) International Education Policy, Vanderbilt University, Nashville, TN, USA that the program failed to achieve its intended objectives. The question is why. They discover that children in the short term were faced with negative economic returns to leaving the labor force and returning to school. It simply didn't pay. However, they also discover that in the long run leaving the labor force and returning to school, the financial returns are positive. They point out that the CCT subsidy was too low and too short (ended too quickly) to have an effect, but were this to change, this CCT program might well have lived up to its expectations. The lesson we might learn from these first two articles concerns the requirements for borrowed policies to work. It matters less that the intentions are honorable and rational; what matters more is that the design is sensible and feasible.

Much has been said about the 'post-2015 agenda', the proposition that new objectives set by nations using the United Nations as their coordinator will define the requirements for change across many dimensions. In his article, John Weidman concentrates on one arena where change is required: the training and preparation of new scholars and practitioners in international education. $\mathrm{He}$ first points out the origin of the current 'framework' and trends beginning with the early work of Rolland Paulston. His point is that this inherited framework needs to shift from static to dynamic. This suggests that the old paradigms and models need now to make way for a rapidly changing environment where effectiveness may be a function of flexibility.

However, important such flexibility may be, it cannot replace excellence which derives from our understanding of educational history. The article by Chong Jae Lee and Yong Kim illustrates this. They review the last 70 years of education policy history in the Republic of Korea in which universal expansion of primary, then secondary, then tertiary levels has been a topic of study around the world. 
They explain how it was done. Prior to May 31, 1995, these accomplishments were achieved through an emphasis on centralized planning and control; after May 31, 1995, the system was freed up to encourage autonomous development, openness, diversity, accountability, consumer-centeredness and market control, a 180 degree shift. They point out, however, that in spite of their creativity and innovative courage, in many ways the new policies are counter-productive. The authors illustrate these counterproductive elements and then call for a new system of normative values to help govern education policy directions in the future. The lesson of this article could not be more important: good public policy requires constant shifts to remain effective.

Higher education is a particularly interesting sector because it requires such different objectives, each implemented simultaneously. Akira Arimoto illustrates this with respect to Japan. His article describes the new government emphasis on university Research and Development (R\&D) and the influence which the mechanisms for this support have on research scholars and university governance in Japan generally. His article describes how the government allocates research funding, evaluates research outcomes and disseminates them with the intention of raising the 'social impact'. One of the important lessons from this article is how different (more authoritarian) the mechanisms of government support may be in Japan as compared to other countries also concerned with R\&D productivity.

The portion of an age cohort attending higher education is higher today than at any time in human history. It continues to rise. At the same time, people are living longer. The issue of 'Lifelong Learning' is used to be analogous to having an unrealistic dream. No longer. Today it represents realistic policy. But how can we differentiate one approach to lifelong learning from another? Is it possible to assess different approaches and different levels of support and to compare one with another in some systematic way? This is the set of issues which seem to motivate Juseuk Kim. This article reviews the current indices of lifelong learning and then suggests a comparison of current indices out of which emerges a way to summarize these different indices in a systematic pattern. The proposed result is a suggestion for how to compare lifelong learning policies across countries and across time. Policy makers in the future may use this index to compare the competitiveness of lifelong learning policies internationally.

As a region, Asia has multiple continuities and overlaps in culture, language, technologies, music, art, religions and philosophy. The question raised by Molly Lee concerns the common philosophical underpinnings and practices within contemporary education policies on access, efficiency, equity, identity, quality and relevance. She discovers that the overlaps are tangible, and they include not only common purposes but dilemmas and trade-offs. The lesson from this article derives from Asia, but might be relevant to much wider geographical boundaries. Perhaps the term 'globalization' is overused and inappropriately used; but it may be an appropriate term to utilize in the search for common philosophical underpinnings of education policy and practices.

Decentralization is an illustration of a global trend in policy reform. It certainly is a vivid illustration of policy borrowing. The rationale is simple: it assumes that the current situation begins with control from the center, control of virtually everything: pedagogy, materials, financing, recruitment, promotion, transfer, assessment, evaluation, licensing. It also assumes that decisions made in the classroom or at the school level are more efficient because the professionals are closer to students. SungHyun Cha describes the effects of decentralization policies when applied to the Republic of Korea. One such effect seems to have been a rise in conflict between local and national authorities. The key issues and dilemmas behind this conflict are identified. The struggles played out in court between 2010 and 2014 are described in detail. It is concluded that the conflicts stemmed from circumstances where the authority was ambiguous, where there were differences in educational and political theory and where the mechanisms to adjudicate conflicts were inadequate. These (quite sensible) observations could also be used to better understand the results of decentralization policies generally.

Ever since Hatakenaka's unique historical study of the origin of university/industry partnerships (Hatakenaka 2004), we have come to understand the role which defense research had in the USA during and following WWII in which universities were asked to openly compete for the opportunity to conduct publicly funded research. The continuation of this mechanism following WWII in the USA and its adaptations (often imperfect) in the UK and in Japan form the underlying basis for our understanding of how universities might be of assistance to public agencies and to the private sector and the dangers and trade-offs of these external university relationships. Dian-Fu Chang and Hung-Jen Weng continue to explore this issue in Taiwan. They are interested in the influence of heterogeneity in graduate institutions on university-industry collaboration. They define heterogeneity in terms of faculty position, nationality and specialization (expertise). They discover that greater heterogeneity is associated with greater university/industry collaboration and make some recommendations as to the optimal heterogeneity for that purpose. The lesson here is not so simple, however. Much of the success, at least in the USA, with respect to effective university/industry collaboration is affected by organizational mission: research universities have one mission, and 
teaching universities and community colleges have different (and equally laudable) missions. University/industry partnerships are often defined by the degree to which there is opportunity within industry which would support the particular mission of the educational organization.

Human capital has been the dominant organizing principle of the education sector since the 1960s. Several Nobel Prizes have been awarded to scholars concentrating on how human capital is defined, how it operates and how it is maximized. Human capital has been the purposes of educational lending of the World Bank, the regional development banks, agencies of the UN, bilateral development assistance agencies and most governments. No longer. Since the awarding of a Nobel Prize to Amartya Sen, the terms of education have begun to expand to include concepts beyond human capital, traditionally defined. Kwangsu Mok and Wongyu Jeong explore this topic. They are interested in Sen's 'capability approach' to education and ethical development. Sen's argument (and mine) is that schooling main purpose is not instrumental by providing technical knowledge and skills but rather the ingredients underlying social consensus (Heyneman 2000, 2002/2003). In spite of the relevance of Sen's theories of ethical development, however, the authors conclude that they are inadequate because they do not include questions of how they are to be implemented. Sen's theories provide no guidance, for instance, in the potential conflict of roles, different purposes of education, nor how it is to be taught.
They suggest that the intrinsic value of education should be made more clear and that the noneconomic roles of education (such as social cohesion) should be more explicit and prioritized with respect to economic and social development. This would imply, for instance, that vocational or engineering skills may be less important than good citizenship in the pursuit of economic growth and general prosperity. This may in fact be true, and if so, may well be revolutionary for the countries in the Asia region.

The overall impact of the articles in this issue of the APER may be considerable. They represent new directions in orientation, new sophistication in methods of evidential substantiation and world-class arenas of innovation not only for Asia, but for the world.

\section{References}

Hatakenaka, Sachi. (2004). University-industry partnerships in MIT, Cambridge, and Tokyo: Storytelling across boundaries. New York: Routledge.

Heyneman, S. P. (2000). From the party/state to multi-ethnic democracy: Education and social cohesion in the Europe and Central Asia Region. Educational Evaluation and Policy Analysis, 21(4), 173-191. (summer).

Heyneman, S. P. (2002/2003). Defining the influence of education on social cohesion. International Journal of Educational Policy, Research and Practice, 3(4), 73-97. (winter). 